\title{
Dietary patterns in pregnancy and respiratory and atopic outcomes in childhood
}

\author{
S O Shaheen, ${ }^{1}$ K Northstone, ${ }^{2}$ R B Newson, ${ }^{1}$ P M Emmett, ${ }^{3}$ A Sherriff, ${ }^{4}$ A J Henderson ${ }^{3}$
}

\begin{abstract}
- Additional tables are published online only at http:// thorax.bmj.com/content/vol64/ issue5

${ }^{1}$ Respiratory Epidemiology and Public Health Group, National Heart and Lung Institute, Imperial College London, London, UK; ${ }^{2}$ Avon Longitudinal Study of Parents and Children (ALSPAC), Department of Social Medicine, University of Bristol, Bristol, UK; ${ }^{3}$ Department of Community-Based Medicine, University of Bristol, Bristol, UK;

${ }^{4}$ Community Oral Health,

Glasgow Dental School, University of Glasgow, Glasgow, UK
\end{abstract}

Correspondence to: Dr S O Shaheen, Respiratory Epidemiology and Public Health Group, National Heart and Lung Institute, Imperial College London, Emmanuel Kaye Building, Manresa Road, London SW36LR, UK; s.shaheen@ imperial.ac.uk

Received 15 September 2008 Accepted 7 January 2009

Published Online First

12 February 2009

\section{ABSTRACT}

Background: Studies of the relation between maternal diet in pregnancy and respiratory and atopic outcomes in the offspring have focused on the effects of individual nutrients and foods rather than dietary patterns. A study was undertaken to determine whether dietary patterns in pregnancy are related to childhood asthma and related outcomes.

Methods: In a population-based birth cohort, the Avon Longitudinal Study of Parents and Children (ALSPAC), dietary patterns in pregnancy previously identified using principal components analysis ("health conscious",

"traditional", "processed", "vegetarian" and "confectionery") were related to early wheezing phenotypes and eczema; wheezing, hay fever, eczema, doctor-diagnosed asthma, atopy and total $\lg E$ at 7 years; lung function and bronchial responsiveness at 8-9 years. In regression models, confounders were controlled for using propensity scores.

Results: Univariately, the "health conscious" pattern was positively associated with eczema, total lgE, forced expiratory volume in $1 \mathrm{~s}$ and forced expiratory flow and negatively associated with early wheezing and asthma (unadjusted odds ratios per standard deviation increase in pattern score for early persistent wheeze and asthma: $0.78(95 \% \mathrm{Cl} 0.70$ to 0.87$), \mathrm{p}=7.3 \times 10^{-6}, \mathrm{~N}=8886$ and 0.90 (95\% Cl 0.84 to 0.97$), p=0.007, N=7625$, respectively). The "processed" pattern was positively associated with early wheezing and negatively associated with atopy and forced vital capacity. On controlling for confounders, the effects were substantially attenuated and became non-significant (adjusted odds ratios for the associations of the "health conscious" pattern with early persistent wheeze and asthma: 1.00 (0.86 to 1.16), $p=0.99$ and 0.95 (0.86 to 1.04 ), $p=0.27$, respectively). Conclusions: In this cohort, dietary patterns in pregnancy did not predict asthma and related outcomes in the offspring after controlling for confounders.

Epidemiological studies of diet and respiratory and atopic diseases have focused largely on relations with intakes of individual nutrients and foods or food groups. ${ }^{1}$ A major limitation with this methodology is that intakes of dietary components are highly correlated, and chance findings may arise from the multiple statistical comparisons which need to be carried out. An alternative and less reductionist approach commonly used to investigate associations between diet and cancer, heart disease and diabetes is to explore associations using dietary patterns. This can be done either by using predefined scores, as used to describe a "Mediterranean" diet, or by data-driven methods such as principal components analysis (PCA). ${ }^{2-4}$ The PCA approach has the advantage of reducing a large number of correlated dietary measurements down to a small number of overall dimensions of diet which are uncorrelated. Another advantage may be that dietary patterns analysis takes account of interactions between nutrients, thus allowing consideration of the effect of the whole diet.

Prospective studies in adults have recently reported relations of dietary patterns identified using PCA with respiratory disease outcomes. One found that a "meat-dim sum" dietary pattern was associated with an increased risk of chronic bronchitis symptoms in a Singapore Chinese population..$^{5}$ Others reported that a "prudent" dietary pattern (high intake of fruits, vegetables, fish and whole grain products) was associated with a reduced risk of chronic obstructive pulmonary disease in men and women in the USA, and a "western" dietary pattern (high intake of refined grains, cured and red meats, desserts and French fries) was associated with an increased risk. ${ }^{67}$ None of these studies found associations with adultonset asthma.

There is increasing interest in the role of maternal diet in pregnancy in relation to respiratory and atopic outcomes in the offspring, and various associations with individual nutrients ${ }^{8-12}$ and foods ${ }^{13-15}$ have been reported. While recent studies have suggested that a predefined "Mediterranean" diet during pregnancy and childhood might have protective effects on childhood wheezing and allergic outcomes, ${ }^{16}{ }^{17}$ we are not aware of any data on possible effects of maternal dietary patterns identified using PCA on childhood respiratory and atopic outcomes. We have therefore examined this in a population-based birth cohort, the Avon Longitudinal Study of Parents and Children (ALSPAC), in which five dietary patterns in pregnancy have previously been identified. ${ }^{18}$

\section{METHODS}

ALSPAC is a population-based birth cohort established in the former county of Avon, UK by recruitment of 14541 pregnant women who were resident in Avon and had expected dates of delivery between 1 April 1991 and 31 December 1992 There were 14062 live-born children. The study protocol has been described previously ${ }^{19-22}$ and further information is available on the ALSPAC website (http://www.alspac.bris.ac.uk).

\section{Outcomes}

The 12-month prevalence of eczema at 2.5 years was defined on the basis of a positive response to the question: "Has your child had an itchy dry skin rash in joints and creases of his/her body (eg, 
behind the knees, under the arms) since he/she was 18 months old?". ${ }^{23}$ Information on wheezing in the child at 3.5 years was obtained by asking the mother at 3.5 years: "In the last 12 months has he/she had any periods when there was wheezing with whistling on his/her chest when he/she breathed?" A similar question at 6 months of age asked about wheezing since birth, and we used the information from these two periods to identify children with four mutually exclusive patterns of wheezing that we have shown to be associated with different risk factors: non-wheezers, transient infant wheezers, later onset wheezers and persistent wheezers. ${ }^{24}$

When the children were 7.5 years old the mothers were asked: "Has your child had any of the following in the past 12 months: wheezing; asthma; eczema; hay fever?". Children were defined as having current doctor-diagnosed asthma at 7.5 years (primary outcome of interest) if mothers responded positively to the question: "Has a doctor ever actually said that your study child has asthma?" and positively to one or both of the questions on wheezing and asthma in the past 12 months. $44 \%$ of children fulfilling this definition of asthma demonstrated bronchial hyper-responsiveness (BHR) as defined by a fall in forced expiratory volume in $1 \mathrm{~s}\left(\mathrm{FEV}_{1}\right)$ of $20 \%$ or more following methacholine challenge up to and including the maximum dose $\left(\mathrm{PD}_{20} \leqslant 1.2 \mathrm{mg}\right)$ and $52 \%$ were atopic. We defined sub-phenotypes of asthma with and without atopy and with and without BHR.

Atopy at 7 years was defined as a positive reaction (maximum diameter of any detectable weal) to Dermatophagoides pteronyssinus, cat or grass (after subtracting positive saline reactions from histamine and allergen weals and excluding children unreactive to $1 \%$ histamine). Serum total $\operatorname{IgE}(\mathrm{kU} / \mathrm{l})$ was measured by fluoroimmunoassay using the Pharmacia UNICAP system (Pharmacia and Upjohn Diagnostics AB, Uppsala, Sweden).

At 8-9 years of age, pulmonary function was measured using a Vitalograph 2120 electronic spirometer with a computer-based on-screen incentive (Vitalograph, Maids Moreton, UK). The tests adhered to American Thoracic Society criteria for standardisation and reproducibility of flow-volume measurement, ${ }^{25}$ with the exception of ATS recommendations for duration of expiration; ${ }^{26}$ as many children did not fulfil forced expiratory time $>6 \mathrm{~s}$ end of test criteria, a minimal volume change over the final second was used.

Outcomes included $\mathrm{FEV}_{1}, \mathrm{FVC}, \mathrm{FEF}_{25-75}$ and the $\mathrm{FEF}_{25-75}$ / FVC ratio (proposed as a measure of dysynaptic lung growth ${ }^{27}$ ), adjusted for gender, age and height and expressed in standard deviations (SDs). ${ }^{28}$ Bronchial responsiveness (BR) to methacholine was measured using the method of Yan. ${ }^{29}$ Saline $(0.9 \%)$ solution was administered and a post-saline $\mathrm{FEV}_{1}$ measurement was used as the baseline. Subsequently, eight doubling doses of methacholine from 0.05 to $6.1 \mu \mathrm{mol}$ were given at $1 \mathrm{~min}$ intervals with repeat measurement of $\mathrm{FEV}_{1}$ after each dose. The challenge continued until the $\mathrm{FEV}_{1}$ decreased by $>20 \%$ from baseline or the maximum dose of methacholine had been given. $\mathrm{BR}$ was expressed as the dose-response slope (percentage decline in $\mathrm{FEV} / \mu \mathrm{mol}$ methacholine). The $\mathrm{FEV}_{1}$ following each dose of methacholine was expressed as a percentage of baseline $\mathrm{FEV}_{1}$, and a linear regression (dose-response) slope of relative $\mathrm{FEV}_{1}$ with respect to cumulative methacholine dose was calculated for each subject and expressed as percentage per $\mu \mathrm{mol}$ methacholine. To prevent the analysis from being dominated by extreme positive and negative slopes based on small numbers of observations, we recoded all negative slopes to $0 \% / \mu \mathrm{mol}$ and all slopes above $50 \% / \mu \mathrm{mol}$ to $50 \% / \mu \mathrm{mol}$ to derive a truncated slope, and then added $0.1 \% / \mu \mathrm{mol}$ to these truncated slopes to derive a transformed slope whose geometric means (GMs) and $\mathrm{GM}$ ratios were estimated in the statistical analysis. A higher GM denotes a greater level of BR.

\section{Maternal diet in pregnancy and dietary patterns}

At 32 weeks of pregnancy, mothers completed a food-frequency questionnaire (FFQ) which comprised 110 questions. Mothers were asked about their current weekly frequency of consumption of 43 food groups and food items, and about daily consumption of a further eight basic foods. The foods chosen were based on those used by Yarnell et $a^{30}$ and modified in the light of a more recent weighed dietary survey. ${ }^{31}$ Additional questions asked about the types of certain foods used and about the ways in which food was prepared and eaten. ${ }^{32}$ Information on portion size was not collected but, as nutrient intakes were not being estimated in this study, portion sizes are not relevant. Five dietary patterns in pregnancy have been previously identified in this cohort using PCA: "health conscious", "traditional", "processed", "vegetarian" and "confectionery". ${ }^{18}$ Dietary pattern scores were expressed in standard deviation units. Each mother was represented in each of these five mutually independent scores.

The five patterns loaded highly on the following foods:

- "Health conscious": salad, fruit, fruit juices, rice, pasta, oat/ bran based breakfast cereals, fish, pulses, cheese, non-white bread.

- "Traditional": vegetables, red meat, poultry.

- "Processed": meat pies, sausages, burgers, fried foods, pizza, chips, crisps, white bread, eggs, baked beans.

- "Vegetarian": meat substitutes, pulses, nuts, herbal tea.

- "Confectionery": chocolate, sweets, biscuits, cakes, puddings.

A summary of highest factor loadings is shown in table 1. Associations between these patterns and nutrient intakes have also been described previously. ${ }^{33}$

\section{Statistical methods}

The analyses included all cohort children for whom maternal dietary pattern and childhood outcome data were available. For each dietary pattern we defined propensity scores ${ }^{34}$ using linear regression models with each pattern as the predicted variable and a list of confounders as predictive factors. The propensity score is a summary measure of the "exposure-proneness" of a subject based on a list of confounding variables, and is used to model out the collective and cumulative confounding effect of those confounders as completely as possible without attempting to measure individual confounder effects on the outcome. The confounders were: maternal factors during pregnancy (energy intake, maximum smoked, infections, antibiotics and paracetamol); other maternal factors (educational level, housing tenure, financial difficulties, pre-pregnancy body mass index (BMI), ethnicity, age, parity, history of asthma, eczema, rhinoconjunctivitis, migraine); sex of child, gestational age, breast fed in first 6 months, day care at 8 months, multiple pregnancy, pets in infancy, damp/condensation/mould, child exposed to environmental tobacco smoke at weekends, season of birth, season of FFQ completion, birth weight, head circumference, birth length. For later childhood outcomes we controlled additionally for number of younger siblings and child's BMI at age 7 (see table E1 in online supplement for frequencies of confounders). For each propensity score the cohort was split into 64 propensity percentile groups of roughly equal size. Dietary pattern scores were analysed separately as 
Table 1 Factor loadings of various food items in the five principal dietary components identified (only loadings above 0.3 and -0.3 are shown)

\begin{tabular}{|c|c|c|c|c|c|}
\hline $\begin{array}{l}\text { Food item } \\
\text { (variance explained) }\end{array}$ & $\begin{array}{l}\text { "Health conscious" } \\
(10.6 \%)\end{array}$ & $\begin{array}{l}\text { "Traditional" } \\
(8.2 \%)\end{array}$ & $\begin{array}{l}\text { "Processed" } \\
(4.9 \%)\end{array}$ & $\begin{array}{l}\text { "Confectionery" } \\
(4.0 \%)\end{array}$ & $\begin{array}{l}\text { "Vegetarian" } \\
(3.6 \%)\end{array}$ \\
\hline White bread & -0.535 & & 0.367 & & \\
\hline Non-white bread & 0.615 & & -0.323 & & \\
\hline Biscuits & & & & 0.603 & \\
\hline Puddings (expand) & & & & 0.389 & \\
\hline Cakes/buns & & & & 0.559 & \\
\hline Meat pies & & & 0.538 & & \\
\hline Sausages, burgers & & & 0.565 & & \\
\hline Fried foods & & & 0.574 & & \\
\hline Pizza & & & 0.349 & & \\
\hline Fish & 0.457 & & & & \\
\hline Eggs & & & 0.403 & & \\
\hline Chips & & & 0.561 & & \\
\hline Roast potatoes & & & 0.388 & & \\
\hline Potatoes (not chips) & & 0.321 & & & \\
\hline Pasta & 0.578 & & & & \\
\hline Rice & 0.543 & & & & \\
\hline Baked beans & & & 0.413 & & \\
\hline Leafy green vegetables & & 0.809 & & & \\
\hline Other green vegetables & & 0.799 & & & \\
\hline Carrots & & 0.704 & & & \\
\hline Other root vegetables & & 0.606 & & & \\
\hline Peas & & 0.352 & & & \\
\hline
\end{tabular}

Table adapted from Northstone et al. ${ }^{18}$

continuous effects (per SD of diet pattern score) using regression (logistic for binary outcomes, multinomial for wheezing phenotypes, linear on the logs for total IgE and BR slope, and untransformed linear for lung function outcomes) using Huber variances throughout. In view of the multiple exposures and outcomes, the $\mathrm{p}$ values for the adjusted analyses were entered into the Simes procedure, controlling the false discovery rate (FDR) at 0.25 to define a discovery set that could be considered "statistically significant", given the number of associations measured. ${ }^{35}$ We also repeated the analyses excluding birth anthropometric variables, gestational age and child's BMI at 7 years from the calculation of the propensity scores, as it is possible that these factors may be on the causal pathway rather than confounders. ${ }^{36}$

\section{RESULTS}

Table E1 in the online supplement shows the relation of the dietary patterns to potential confounders. All patterns except "vegetarian" were associated with energy intake. The "health conscious" and "processed" patterns were associated with maternal age, parity, educational level, housing tenure, financial difficulties, smoking in pregnancy and environmental tobacco exposure, breast feeding and day care. Table 2 shows the prevalences of the categorical outcomes of interest. Table E2 in the online supplement shows the mean dietary pattern scores according to the presence or absence of reported and objective outcomes as follow-up of the cohort progressed. Mothers for whom outcome data were missing for the offspring had lower mean scores for the "health conscious" pattern and higher scores for the "processed" pattern.

In unadjusted analyses the "health conscious" dietary pattern in pregnancy was associated with an increased risk of early and later eczema (table 3 and table E3 in the online supplement), atopy (table 5) and raised total IgE (table E4 in the online supplement). It was also associated with a lower risk of early wheezing (table 3), particularly the transient infant and persistent phenotypes (table 4), a lower risk of later asthma (table 5) and with higher $\mathrm{FEV}_{1}$ (table E5 in the online supplement) and $\mathrm{FEF}_{25-75}$ (data not shown). In contrast, the "processed" dietary pattern was associated with an increased risk of early wheezing (table 3), particularly the transient infant and persistent phenotypes (table 4), and lower FVC (table E5 in the online supplement). It was also associated with a lower risk of atopy (table 5). The "vegetarian" pattern was associated 
Table 2 Prevalence of categorical outcomes

\begin{tabular}{lc}
\hline Outcome & No (\%) \\
\hline Eczema at 2.5 years & $7007(73.63)$ \\
No & $2509(26.37)$ \\
Yes & \\
Wheezing at 3.5 years & $7708(86.74)$ \\
$\quad$ No & $1178(13.26)$ \\
Yes & \\
Early wheezing phenotypes & $6492(73.06)$ \\
$\quad$ Never & $1216(13.68)$ \\
Transient infant & $735(8.27)$ \\
Later onset & $443(4.99)$ \\
Persistent & \\
Outcomes at 7.5 years & \\
Eczema & $6447(83.80)$ \\
No & $1246(16.20)$ \\
Yes & \\
Hay fever & $7001(91.23)$ \\
No & $673(8.77)$ \\
Yes & \\
Doctor-diagnosed asthma & $6698(87.84)$ \\
No & $927(12.16)$ \\
Yes & \\
Wheezing & $6885(89.33)$ \\
No & $822(10.67)$ \\
Yes & \\
Atopy at 7 years & $4775(78.47)$ \\
No & $1310(21.53)$ \\
Yes & \\
\hline
\end{tabular}

univariately with raised total IgE (table E4 in online supplement).

On controlling for confounders, most of these effects were substantially attenuated towards the null, although a few associations were little changed or became stronger and remained significant at the $5 \%$ level. These included relations of the "health conscious" and "vegetarian" patterns with IgE (see table E4 in the online supplement) and the "processed" pattern with FVC (see table E5 in the online supplement). However, when all the adjusted comparisons were entered into the Simes procedure, the results suggested that all of these associations could have arisen by chance. Removing variables which might be on the causal path (birth anthropometry, gestational age, child's BMI) from the adjusted models did not alter the main findings.

\section{DISCUSSION}

To our knowledge this is the first study to examine the relations of dietary patterns in pregnancy identified by PCA to respiratory and atopic outcomes in childhood. While we found that the "health conscious" and "processed" patterns were strongly associated with a number of outcomes univariately, most associations were greatly attenuated when we controlled for potential confounders. We have previously shown that these dietary patterns are clearly socially determined. ${ }^{18}$ In particular, the "health conscious" component was associated with higher socioeconomic status, as indicated by higher maternal educational levels, owner-occupied housing, fewer financial difficulties and older maternal age. In contrast, the "processed" pattern showed associations which were the reverse of these. These two patterns also showed associations in opposite directions with parity and with smoking in the third trimester. Given that low maternal age, smoking in pregnancy and living in rented housing are associated with an increased risk of early wheezing in this cohort, ${ }^{24}$ it is not surprising that the "health conscious" and "processed" patterns were univariately associated negatively and positively with this outcome, respectively. Nor was it unexpected that eczema, which is associated with affluence, ${ }^{37}$ was positively associated univariately with the "health conscious" pattern.

Comparison with other studies of maternal diet in pregnancy and childhood respiratory and atopic outcomes is difficult as no other studies have analysed dietary patterns using PCA. However, while our "health conscious" pattern (which loaded highly on fish, cereal, pulses, cheese, salad and fruit) has some similarities with a "Mediterranean" diet, our findings for this dietary pattern are not in keeping with a previous report of a protective effect of a Mediterranean diet in pregnancy on persistent wheeze and atopic outcomes at 6.5 years of age. ${ }^{16}$ Also, in contrast to studies suggesting that eating fish in

Table 3 Relation between dietary patterns in pregnancy and early eczema and wheezing in the offspring

\begin{tabular}{|c|c|c|c|c|}
\hline & Unadjusted & \multirow[b]{2}{*}{ p Value } & \multirow{2}{*}{$\begin{array}{l}\text { Adjusted* } \\
\mathrm{OR} \dagger(95 \% \mathrm{CI})\end{array}$} & \multirow[b]{2}{*}{ p Value } \\
\hline & $\mathrm{OR} \dagger(95 \% \mathrm{CI})$ & & & \\
\hline \multicolumn{5}{|c|}{ Eczema at 2.5 years $(n=9516)$} \\
\hline Health conscious & 1.12 (1.07 to1.17) & $2.2 \times 10^{-6}$ & $1.06(0.99$ to 1.12$)$ & 0.08 \\
\hline Traditional & $0.99(0.95$ to 1.04$)$ & 0.82 & $1.00(0.95$ to 1.05$)$ & 0.96 \\
\hline Processed & $0.95(0.90$ to 1.00$)$ & 0.06 & $0.97(0.91$ to 1.03$)$ & 0.28 \\
\hline Confectionery & $1.02(0.97$ to 1.07$)$ & 0.43 & $1.03(0.97$ to 1.08$)$ & 0.37 \\
\hline Vegetarian & $0.98(0.94$ to 1.03$)$ & 0.43 & $0.99(0.94$ to 1.04$)$ & 0.58 \\
\hline \multicolumn{5}{|c|}{ Wheezing at 3.5 years $(n=8886)$} \\
\hline Health conscious & $0.90(0.84$ to 0.96$)$ & $<0.001$ & $0.96(0.88$ to 1.05$)$ & 0.37 \\
\hline Traditional & $0.99(0.93$ to 1.06$)$ & 0.84 & $1.00(0.93$ to 1.07$)$ & 0.90 \\
\hline Processed & $1.14(1.07$ to 1.22$)$ & $<0.001$ & $1.02(0.94$ to 1.10$)$ & 0.69 \\
\hline Confectionery & $1.00(0.94$ to 1.07$)$ & 0.91 & $0.98(0.91$ to 1.06$)$ & 0.61 \\
\hline Vegetarian & $0.99(0.93$ to 1.05$)$ & 0.80 & $0.97(0.91$ to 1.04$)$ & 0.42 \\
\hline
\end{tabular}


Table 4 Relation between dietary patterns in pregnancy and early wheezing phenotypes in the offspring $(\mathrm{n}=8886)$

\begin{tabular}{|c|c|c|c|c|}
\hline & Unadjusted & \multirow[b]{2}{*}{ p Value } & \multirow{2}{*}{$\begin{array}{l}\text { Adjusted* } \\
\mathrm{OR} \dagger(95 \% \mathrm{CI})\end{array}$} & \multirow[b]{2}{*}{ p Value } \\
\hline & $\mathrm{OR} \dagger(95 \% \mathrm{CI})$ & & & \\
\hline \multicolumn{5}{|c|}{ Transient infant wheeze } \\
\hline Health conscious & $0.88(0.83$ to 0.94$)$ & $<0.001$ & $0.98(0.90$ to 1.06$)$ & 0.57 \\
\hline Traditional & $0.94(0.88$ to 1.01$)$ & 0.076 & 0.95 (0.89 to 1.02$)$ & 0.16 \\
\hline Processed & $1.12(1.05$ to 1.20$)$ & $<0.001$ & $0.99(0.91$ to 1.08$)$ & 0.87 \\
\hline Confectionery & $1.02(0.96$ to 1.09$)$ & 0.50 & $1.03(0.95$ to 1.10$)$ & 0.51 \\
\hline Vegetarian & $1.00(0.94$ to 1.07$)$ & 0.93 & $1.00(0.94$ to 1.06$)$ & 0.91 \\
\hline \multicolumn{5}{|l|}{ Later onset wheeze } \\
\hline Health conscious & $0.94(0.87$ to 1.02$)$ & 0.13 & $0.93(0.84$ to 1.03$)$ & 0.19 \\
\hline Traditional & $1.00(0.93$ to 1.09$)$ & 0.92 & $1.00(0.92$ to 1.09$)$ & 0.95 \\
\hline Processed & $1.10(1.01$ to 1.20$)$ & 0.03 & $1.03(0.93$ to 1.13$)$ & 0.61 \\
\hline Confectionery & $1.00(0.93$ to 1.08$)$ & 0.99 & $0.96(0.87$ to 1.06$)$ & 0.41 \\
\hline Vegetarian & $0.94(0.87$ to 1.02$)$ & 0.16 & $0.92(0.85$ to 1.00$)$ & 0.06 \\
\hline \multicolumn{5}{|l|}{ Persistent wheeze } \\
\hline Health conscious & $0.78(0.70$ to 0.87$)$ & $7.3 \times 10^{-6}$ & $1.00(0.86$ to 1.16$)$ & 0.99 \\
\hline Traditional & $0.95(0.85$ to 1.06$)$ & 0.36 & $0.96(0.86$ to 1.08$)$ & 0.51 \\
\hline Processed & 1.27 (1.15 to 1.40$)$ & $4.3 \times 10^{-6}$ & $1.00(0.88$ to 1.13$)$ & 0.98 \\
\hline Confectionery & $1.02(0.91$ to 1.14$)$ & 0.75 & $1.02(0.90$ to 1.16$)$ & 0.72 \\
\hline Vegetarian & $1.07(0.98$ to 1.17$)$ & 0.14 & $1.06(0.96$ to 1.16$)$ & 0.27 \\
\hline
\end{tabular}

${ }^{*}$ Controlling for energy intake, maximum smoked, infections, antibiotics and paracetamol use during pregnancy; maternal educational level, housing tenure, financial difficulties, pre-pregnancy body mass index, ethnicity, age, parity, history of asthma, eczema, rhinoconjunctivitis, migraine; sex of child, gestational age, breast fed in first 6 months, day care at 8 months, multiple pregnancy, pets in infancy, damp/condensation/mould, child exposed to environmental tobacco smoke at weekends, season of birth, season of food frequency questionnaire completion, birth weight, head circumference, birth length.

$\dashv$ Per standard deviation of dietary pattern score.

Reference outcome $=$ non-wheezers.

Table 5 Relation between dietary patterns in pregnancy and asthma, wheezing and atopy in the offspring

\begin{tabular}{|c|c|c|c|c|}
\hline & Unadjusted & & Adjusted* & \\
\hline & $\mathrm{OR} \dagger(95 \% \mathrm{Cl})$ & p Value & $\mathrm{OR} \dagger(95 \% \mathrm{Cl})$ & p Value \\
\hline Asthma at 7.5 yea & $=7625)$ & & & \\
\hline Health conscious & 0.90 (0.84 to 0.97$)$ & 0.007 & 0.95 (0.86 to 1.04 ) & 0.27 \\
\hline Traditional & $0.97(0.90$ to 1.04$)$ & 0.39 & 0.96 (0.89 to 1.04$)$ & 0.35 \\
\hline Processed & 1.05 (0.97 to 1.13$)$ & 0.23 & $0.98(0.90$ to 1.07$)$ & 0.68 \\
\hline Confectionery & 0.98 (0.91 to 1.06$)$ & 0.65 & $1.00(0.91$ to 1.08$)$ & 0.93 \\
\hline Vegetarian & $1.03(0.97$ to 1.10$)$ & 0.30 & 1.02 (0.95 to 1.09 ) & 0.62 \\
\hline Wheezing at $7.5 y$ & $=7707)$ & & & \\
\hline Health conscious & $1.00(0.93$ to 1.08$)$ & 0.99 & 1.00 (0.91 to 1.11$)$ & 0.94 \\
\hline Traditional & $1.01(0.94$ to 1.09$)$ & 0.75 & $1.00(0.92$ to 1.08$)$ & 0.99 \\
\hline Processed & $0.97(0.90$ to 1.06$)$ & 0.54 & $0.92(0.84$ to 1.01$)$ & 0.098 \\
\hline Confectionery & 0.99 (0.91 to 1.07$)$ & 0.78 & $1.02(0.93$ to 1.12$)$ & 0.70 \\
\hline Vegetarian & 1.04 (0.97 to 1.11$)$ & 0.31 & $1.02(0.95$ to 1.10$)$ & 0.62 \\
\hline Atopy at 7 years & & & & \\
\hline Health conscious & 1.07 (1.01 to 1.14$)$ & 0.03 & 0.95 (0.88 to 1.04$)$ & 0.26 \\
\hline Traditional & $0.98(0.92$ to 1.05$)$ & 0.61 & 0.98 (0.91 to 1.05$)$ & 0.54 \\
\hline Processed & $0.88(0.82$ to 0.95$)$ & $<0.001$ & $0.93(0.85$ to 1.01$)$ & 0.08 \\
\hline Confectionery & $1.04(0.97$ to 1.10$)$ & 0.26 & $1.07(0.99$ to 1.15$)$ & 0.09 \\
\hline Vegetarian & $1.03(0.97$ to 1.10$)$ & 0.28 & $1.02(0.96$ to 1.09$)$ & 0.44 \\
\hline
\end{tabular}

*Controlling for energy intake, maximum smoked, infections, antibiotics and paracetamol use during pregnancy; maternal educational level, housing tenure, financial difficulties, pre-pregnancy body mass index, ethnicity, age, parity, history of asthma, eczema, rhinoconjunctivitis, migraine; sex of child, gestational age, breast fed in first 6 months, day care at 8 months, multiple pregnancy, pets in infancy, damp/condensation/mould, child exposed to environmental tobacco smoke at weekends, season of birth, season of food frequency questionnaire completion, birth weight, head circumference, birth length; number of younger siblings and child's BMI at age 7.

$\uparrow$ Per standard deviation of dietary pattern score. 
pregnancy protects against childhood eczema and atopy, ${ }^{13-15}$ we found that the "health conscious" pattern was associated univariately with an increased risk of eczema and atopy. We will report analyses of the relations of maternal intake of specific nutrients and foods in pregnancy to respiratory and atopic outcomes in childhood elsewhere.

As expected, attrition of the cohort during follow-up, as with other birth cohorts, was greatest among families of lower socioeconomic status. Hence, it was unsurprising that mothers for whom outcome data were missing had lower mean scores for the "health conscious" pattern and higher scores for the "processed" pattern. Without outcome data for these individuals we cannot determine whether the associations measured in those with complete data are representative of those in the entire cohort. However, the potential for losses to follow-up to bias our findings is likely to be less for associations with reported outcomes such as asthma than for associations with objective outcomes such as IgE and BR, as data were more complete for the former (see table E2 in the online supplement).

An unexpected association after controlling for confounders was the positive relation between a "vegetarian" pattern and total IgE. While this may have arisen by chance given the multiple exposures and outcomes analysed, it would be of interest to see whether this finding, along with the few other associations which achieved nominal significance, can be replicated in other studies. A previous study in this cohort found that vegetarian mothers were more likely to have boys with hypospadias, ${ }^{38}$ and it was suggested that this link might be explained by phyto-oestrogens. Vegetarians have a higher intake and blood levels of phyto-oestrogens than omnivores, ${ }^{39}$ and there are animal data which suggest that exposure to phytooestrogens in early life can increase later IgE production, ${ }^{40}$ although we did not observe an association with atopy.

Although the FFQ that we used has not been formally calibrated against other instruments such as diet diaries, the questionnaire on which it was based had been compared against weighed records, albeit in a different population. ${ }^{30}$ Furthermore, we have confirmed expected strong correlations between maternal intake of oily fish and maternal red blood cell n-3 fatty acid levels, ${ }^{41}{ }^{42}$ and between maternal fish intake and umbilical cord concentrations of mercury, ${ }^{43} 44$ and also a weak correlation between maternal vitamin $\mathrm{D}$ intake and blood vitamin $\mathrm{D}$ levels during pregnancy (unpublished data). Studies which have compared the results of PCA using FFOs with those using diet records have found that the resulting factor loadings and dietary pattern scores were comparable. ${ }^{45-47}$ Our dietary patterns are comparable to those identified in another large population-based study of women of fertile age in southern England. That study, which also used FFQs and PCA, identified "prudent" and "high energy" patterns which were very similar to our "health conscious" and "processed" patterns in terms of the foods which defined these components, and also with respect to sociodemographic and nutrient associations. ${ }^{48} 49$

In conclusion, strong univariate associations between two dietary patterns in pregnancy, identified using PCA, and respiratory and atopic outcomes in the offspring were largely explained by confounding factors. While we are also planning to examine relations of a Mediterranean diet and intake of specific nutrients and foods in pregnancy on these outcomes in ALSPAC, these findings would seem to cast doubt on whether adopting healthier dietary patterns in pregnant women is likely to have a major beneficial impact in asthma prevention and improving the respiratory health of children.
Acknowledgements: The authors thank all the families who took part in this study, the midwives for their help in recruiting them, the whole ALSPAC team which includes interviewers, computer and laboratory technicians, clerical workers, research scientists, volunteers, managers, receptionists and nurses, and Richard Hooper for useful discussions.

Funding: The UK Medical Research Council, the Wellcome Trust and the University of Bristol provide core support for ALSPAC. SOS is an Asthma UK Senior Research Fellow.

\section{Competing interests: None.}

Ethics approval: Ethics approval for all aspects of data collection was obtained from the ALSPAC Law and Ethics Committee (IRB 00003312).

This publication is the work of the authors and SOS and AJH will serve as guarantors for the contents of this paper. KN carried out the initial analyses of dietary patterns; SOS and RBN carried out the current analyses and SOS wrote the first draft of the paper; AS derived the early wheezing phenotypes; AJH was responsible for all clinical respiratory and allergy data collection; PME was responsible for the collection of all nutrition data in pregnancy.

\section{REFERENCES}

1. Tricon S, Willers S, Smit HA, et al. Nutrition and allergic disease. Clin Exp Allergy Reviews 2006;6:117-88.

2. Kant AK. Dietary patterns and health outcomes. J Am Diet Assoc 2004:104:615-35

3. Jacques PF, Tucker KL. Are dietary patterns useful for understanding the role of diet in chronic disease? Am J Clin Nutr 2001;73:1-2.

4. Hu F. Dietary pattern analysis: a new direction in nutritional epidemiology. Curr Opin Lipidol 2002;13:3-9.

5. Butler LM, Koh WP, Lee HP, et al. Prospective study of dietary patterns and persistent cough with phlegm among Chinese Singaporeans. Am J Respir Crit Care Med 2006;173:264-70.

6. Varraso R, Fung $\Pi$, Hu FB, et al. Prospective study of dietary patterns and chronic obstructive pulmonary disease among US men. Thorax 2007;62:786-91.

7. Varraso R, Fung TT, Barr RG, et al. Prospective study of dietary patterns and chronic obstructive pulmonary disease among US women. Am J Clin Nutr 2007:86:488-95.

8. Martindale S, McNeill G, Devereux G, et al. Antioxidant intake in pregnancy in relation to wheeze and eczema in the first two years of life. Am J Respir Crit Care Med 2005;171:121-8.

9. Litonjua AA, Rifas-Shiman SL, Ly NP, et al. Maternal antioxidant intake in pregnancy and wheezing illnesses in children at 2 y of age. Am J Clin Nutr 2006:84:903-11.

10. Devereux G, Turner SW, Craig LCA, et al. Low maternal vitamin E intake during pregnancy is associated with asthma in 5-year-old children. Am J Respir Crit Care Med 2006:174:499-507.

11. Devereux G, Litonjua AA, Turner SW, et al. Maternal vitamin D intake during pregnancy and early childhood wheezing. Am J Clin Nutr 2007;85:853-9.

12. Camargo CA Jr, Rifas-Shiman SL, Litonjua AA, et al. Maternal intake of vitamin D during pregnancy and risk of recurrent wheeze in children at 3 y of age. Am J Clin Nutr 2007;85:788-95.

13. Willers S, Devereux G, Craig L, et al. Maternal food consumption during pregnancy and asthma, respiratory and atopic symptoms in 5-year-old children. Thorax 2007;62:773-9.

14. Romieu I, Torrent M, Garcia-Esteban R, et al. Maternal fish intake during pregnancy and atopy and asthma in infancy. Clin Exp Allergy 2007;37:518-25.

15. Sausenthaler S, Koletzko S, Schaaf B, et al. Maternal diet during pregnancy in relation to eczema and allergic sensitization in the offspring at 2 y of age. Am J Clin Nutr 2007;85:530-7.

16. Chatzi L, Torrent M, Romieu I, et al. Mediterranean diet in pregnancy is protective for wheeze and atopy in childhood. Thorax 2008;63:507-13.

17. Chatzi L, Apostolaki G, Bibakis I, et al. Protective effect of fruits, vegetables and the Mediterranean diet on asthma and allergies among children in Crete. Thorax 2007:62:677-83.

18. Northstone K, Emmett P, Rogers I. Dietary patterns in pregnancy and associations with socio-demographic and lifestyle factors. Eur J Clin Nutr 2008;62:471-9.

19. Golding J, Pembrey M, Jones R, ALSPAC Study Team. ALSPAC-The Avon Longitudinal Study of Parents and Children. I. Study methodology. Paediatr Perinat Epidemiol 2001:15:74-87.

20. Golding J, ALSPAC Study Team. The Avon Longitudinal Study of Parents and Children (ALSPAC) — study design and collaborative opportunities. Eur J Endocrinol 2004;151(Suppl 3):U119-23.

21. Jones RW, Ring $S$, Tyfield $L$, et al. A new human genetic resource: a DNA bank established as part of the Avon longitudinal study of pregnancy and childhood (ALSPAC). Eur J Hum Genet 2000:8:653-60.

22. Pembrey M, ALSPAC Study Team. The Avon Longitudinal Study of Parents and Children (ALSPAC): a resource for genetic epidemiology. Eur J Endocrinol 2004;151(Suppl 3):U125-9.

23. Williams HC, Burney PG, Hay RJ, et al. The UK Working Party's Diagnostic Criteria for Atopic Dermatitis. I. Derivation of a minimum set of discriminators for atopic dermatitis. Br J Dermatol 1994;131:383-96.

24. Sherriff A, Peters TJ, Henderson J, Strachan D, ALSPAC Study Team. Risk factor associations with wheezing patterns in children followed longitudinally from birth to 31/2 years. Int J Epidemiol 2001;30:1473-84.

25. American Thoracic Society. Standardization of spirometry, 1994 update. Am J Respir Crit Care Med 1995:152:1107-36. 
26. Arets HGM, Brackel HJL, van der Ent CK. Forced expiratory manoeuvres in children: do they meet ATS and ERS criteria for spirometry? Eur Respir J 2001;18:655-60.

27. Munakata M, Ohe M, Homma Y, et al. Pulmonary dysanapsis, methacholine airway responsiveness and sensitization to airborne antigen. Respirology 1997:2:113-8.

28. Chinn S, Rona RJ. Height and age adjustment for cross sectional studies of lung function in children aged 6-11 years. Thorax 1992;47:707-14.

29. Yan K, Salome C, Woolcock AJ. Rapid method for measurement of bronchial responsiveness. Thorax 1983;38:760-5.

30. Yarnell JW, Fehily AM, Milbank JE, et al. A short dietary questionnaire for use in an epidemiological survey: comparison with weighed dietary records. Human Nutr Appl Nutr 1983;37:103-12

31. Emmett P, Symes C, Braddon F, et al. Validation of a new questionnaire for assessing habitual intake of starch, non-starch polysaccharides, sugars and alcohol. $J$ Human Nutr Dietet 1992;5:245-53.

32. Rogers I, Emmett P. Diet during pregnancy in a population of pregnant women in South West England. ALSPAC Study Team. Avon Longitudinal Study of Pregnancy and Childhood. Eur J Clin Nutr 1998;52:246-50.

33. Northstone K, Emmett PM, Rogers IS. Dietary patterns in pregnancy and associations with nutrient intakes. Br J Nutr 2008;99:406-15

34. Imai K, Van Dyk DA. Causal inference with general treatment regimes: generalising the propensity score. J Am Stat Assoc 2004;99:854-66.

35. Benjamini Y, Drai D, Elmer G, et al. Controlling the false discovery rate in behavior genetics research. Behav Brain Res 2001:125:279-84.

36. Hernan MA, Hernandez-Diaz S, Werler MM, et al. Causal knowledge as a prerequisite for confounding evaluation: an application to birth defects epidemiology. Am J Epidemiol 2002:155:176-84.

37. Williams HC, Strachan DP, Hay RJ. Childhood eczema: disease of the advantaged? BMJ 1994;308:1132-5.

38. North K, Golding J. A maternal vegetarian diet in pregnancy is associated with hypospadias. The ALSPAC Study Team. Avon Longitudinal Study of Pregnancy and Childhood. BJU Int 2000;85:107-13.
39. Ritchie MR, Cummings JH, Morton MS, et al. A newly constructed and validated isoflavone database for the assessment of total genistein and daidzein intake. Br J Nutr 2007;95:204-13.

40. Guo TL, Auttachoat W, Chi RP. Genistein enhancement of respiratory allergen trimellitic anhydride-induced IgE production by adult B6C3F1 mice following in utero and postnatal exposure. Toxicol Sci 2005;87:399-408.

41. Newson RB, Shaheen SO, Henderson AJ, et al. Umbilical cord and maternal blood red cell fatty acids and early childhood wheezing and eczema. J Allergy Clin Immunol 2004:114:531-7.

42. Williams C, Birch EE, Emmett PM, et al. Stereoacuity at age $3.5 \mathrm{y}$ in children born full-term is associated with prenatal and postnatal dietary factors: a report from a population- based cohort study. Am J Clin Nutr 2001;73:316-22.

43. Shaheen So, Newson RB, Henderson AJ, et al. Umbilical cord trace elements and minerals and risk of early childhood wheezing and eczema. Eur Respir $J$ 2004:24:292-7.

44. Daniels JL, Longnecker MP, Rowland AS, et al and the ALSPAC Study Team, University of Bristol Institute of Child Health. Fish intake during pregnancy and early cognitive development of offspring. Epidemiology 2004;15:394-402.

45. Hu FB, Rimm E, Smith-Warner SA, et al. Reproducibility and validity of dietary patterns assessed with a food-frequency questionnaire. Am J Clin Nutr 1999;69:243-9.

46. Togo $\mathbf{P}$, Heitmann $B L$, rensen $T I A$, et al. Consistency of food intake factors by different dietary assessment methods and population groups. Br J Nutr 2007:90:667-78.

47. Khani BR, Ye W, Terry P, et al. Reproducibility and validity of major dietary patterns among Swedish women assessed with a food-frequency questionnaire. J Nutr 2004:134:1541-5.

48. Robinson SM, Crozier SR, Borland SE, et al. Impact of educational attainment on the quality of young women's diets. Eur J Clin Nutr 2004;58:1174-80.

49. Crozier SR, Robinson SM, Borland SE, et al. Dietary patterns in the Southampton Women's Survey. Eur J Clin Nutr 2006;60:1391-9. 